\title{
The relationship between red-cell distribution width and abnormal left ventricle geometric patterns in patients with untreated essential hypertension
}

\author{
Baris Kilicaslan, Huseyin Dursun, Mehmet Aydin, Cenk Ekmekci and Oner Ozdogan
}

\begin{abstract}
Abnormal left ventricle (LV) geometric patterns are associated with an increased risk of vascular complications of hypertension (HT). The association between red-cell distribution width (RDW) and HT has been recently investigated; however, the relationship between abnormal LV geometric patterns and RDW has not been studied before. The aim of this study was to investigate the relationship between RDW and abnormal LV geometric patterns in patients with untreated essential HT. Measurements were obtained from 139 patients with untreated essential HT (mean age $=51.3 \pm 16.3$ years). Four different geometric patterns (NG, normal geometry; CR, concentric remodeling; $\mathrm{EH}$, eccentric hypertrophy; $\mathrm{CH}$, concentric hypertrophy) were determined according to the LV mass index (LVMI) and relative wall thickness (RWT). RDW, lipid parameters and other biochemical markers were measured in all patients. While the highest RDW values were detected in the $\mathrm{CH}$ group $(P<0.05$, for all), it was similar among the NG, CR and EH groups $(P>0.05$, for all). RDW was associated with age, LVMI and LV geometry in bivariate analysis $(P<0.05$, for all). In a receiver operating characteristic (ROC) curve analysis, a level of RDW $>14.5$ predicted $\mathrm{CH}$ with $81 \%$ sensitivity and $59 \%$ specificity. Age (beta $=0.309, P=0.001$ ), LV geometry type (beta $=0.228$, $\boldsymbol{P}=0.01$ ) and RWT (beta $=-0.278 ; \boldsymbol{P}=0.25$ ) were independent predictors of high RDW in multiple linear regression analysis. In conclusion, the highest RDW values were observed in the $\mathrm{CH}$ group in the untreated essential HT patients. RDW seems to be a useful tool for the prediction of end-organ damage in patients with untreated essential HT. Hypertension Research (2014) 37, 560-564; doi:10.1038/hr.2014.39; published online 6 March 2014
\end{abstract}

Keywords: essential hypertension; left ventricle geometric patterns; left ventricle mass index; red-cell distribution width

\section{INTRODUCTION}

Hypertension (HT) is an important health problem that is associated with considerable cardiovascular $(\mathrm{CV})$ morbidity and mortality related to end-organ damage. It should be adequately treated according to the specific risk factors and clinical conditions of the patient. $^{1,2}$ Left ventricular hypertrophy (LVH) is an important example of end-organ damage in patients with HT.,4 The heart may adapt to HT by developing concentric $\mathrm{LVH}(\mathrm{CH})$, eccentric LVH $(\mathrm{EH})$, concentric left ventricular remodeling $(\mathrm{CR})$ or by retaining a normal left ventricular geometry (NG). ${ }^{3}$ In previous studies it has been shown that increased left ventricular mass (LVM) and abnormal geometry have a strong predictive value for $\mathrm{CV}$ death, myocardial infarction and stroke. ${ }^{3,4}$

Red-cell distribution width (RDW) is a quantitative measure of the variability in the size of circulating erythrocytes, and higher values reflect a more heterogeneous cell population ${ }^{5,6}$ Increased RDW is also related to oxidative stress and the release of cytokines in response to inflammation. ${ }^{7}$ It has been consistently shown that RDW is closely related to the prognosis and long-term adverse events of $\mathrm{CV}$ diseases. ${ }^{8}$
Additionally, previous studies have shown that RDW levels are significantly increased in patients with HT. ${ }^{9-11}$ However, the relation between the RDW level and LV geometric patterns in patients with HT has not been investigated previously. The goal of this study was to investigate the relation between RDW and different LV geometric patterns in patients with untreated essential HT.

\section{METHODS}

\section{Study population}

Participants were recruited from the HT outpatient clinic at the Izmir Tepecik Research and Training Hospital between September 2012 and April 2013. A total of 139 patients ( 60 male, mean age $=51.1 \pm 16.3$ years) who met the criteria of being newly diagnosed with essential HT were enrolled in this crosssectional study. The patients with HT had three clinical blood pressure (BP) measurements $(>140 / 90 \mathrm{~mm} \mathrm{Hg})$ taken at 1-week intervals in the absence of any previous antihypertensive treatment to exclude any pharmacological effects on hemodynamics or ventricular hypertrophy and function. ${ }^{12}$ Echocardiography examinations including 2D, spectral and tissue Doppler measurements were performed, and blood samples were obtained from all 
Table 1 Comparison of baseline, clinical and laboratory characteristics

\begin{tabular}{|c|c|c|c|c|c|c|}
\hline Variables & $N G$ group $(\mathrm{n}=36)$ & $C R$ group $(\mathrm{n}=35)$ & EH group $(\mathrm{n}=30)$ & $\mathrm{CH}$ group $(\mathrm{n}=38)$ & $f$ & P-value \\
\hline AGE (year) & $45.2 \pm 17.6$ & $54.7 \pm 16.8$ & $52.8 \pm 16.4$ & $52.0 \pm 13.8$ & 2.313 & 0.079 \\
\hline Gender (male) & $15(42 \%)$ & $20(57 \%)$ & $14(48 \%)$ & 11 (29\%) & 2.117 & 0.101 \\
\hline $\mathrm{SBP}(\mathrm{mm} \mathrm{Hg})$ & $135.8 \pm 10.5^{a}$ & $138.8 \pm 14.9$ & $140.3 \pm 9.9$ & $145.9 \pm 15.5$ & 3.824 & 0.011 \\
\hline $\mathrm{DBP}(\mathrm{mm} \mathrm{Hg})$ & $84.1 \pm 7.2^{b}$ & $89.8 \pm 10.7$ & $89.1 \pm 9.6$ & $90.6 \pm 11.6$ & 3.197 & 0.026 \\
\hline Pulse (per min) & $78.4 \pm 9.7$ & $79.3 \pm 10.1$ & $75.9 \pm 10.8$ & $78.1 \pm 10.9$ & 0.587 & 0.624 \\
\hline Glucose (mg dl ${ }^{-1}$ ) & $93.1 \pm 20.6$ & $97.9 \pm 22.1$ & $103.7 \pm 28.1$ & $105.7 \pm 42.1$ & 1.111 & 0.348 \\
\hline BUN (mg dl $\left.{ }^{-1}\right)$ & $28.2 \pm 11.2$ & $35.4 \pm 13.8$ & $32.8 \pm 10.3$ & $33.7 \pm 16.7$ & 1.587 & 0.197 \\
\hline Creatinine (mg dl-1) & $0.91 \pm 21$ & $1.06 \pm 0.48$ & $0.98 \pm 0.2$ & $0.93 \pm 0.25$ & 1.288 & 0.282 \\
\hline TChol (mg dl-1) & $214.1 \pm 60.4$ & $219.3 \pm 51.4$ & $196.0 \pm 35.7$ & $203.4 \pm 49.2$ & 0.988 & 0.402 \\
\hline $\mathrm{TG}\left(\mathrm{mg} \mathrm{dl} \mathrm{l}^{-1}\right)$ & $128.3 \pm 56.3^{c}$ & $172.0 \pm 83.1$ & $143.0 \pm 67.5$ & $169.8 \pm 73.3$ & 2.582 & 0.058 \\
\hline HDL-C (mg dl-1) & $48.5 \pm 10.5$ & $44.4 \pm 10.6$ & $42.6 \pm 15.6$ & $43.4 \pm 9.6$ & 1.464 & 0.229 \\
\hline LDL-C (mg dl $\left.{ }^{-1}\right)$ & $140.0 \pm 53.4$ & $140.5 \pm 42.8$ & $124.2 \pm 30.2$ & $126.1 \pm 45.0$ & 0.966 & 0.412 \\
\hline HBG $\left(\mathrm{mg} \mathrm{dl}^{-1}\right)$ & $13.7 \pm 1.6$ & $13.9 \pm 1.7$ & $13.5 \pm 1.6$ & $13.1 \pm 1.9$ & 1.190 & 0.317 \\
\hline HTC (\%) & $40.5 \pm 4.3$ & $42.6 \pm 8.8^{d}$ & $39.6 \pm 4.4$ & $38.6 \pm 5.1$ & 2.469 & 0.066 \\
\hline WBC $\left(\mathrm{Kul}^{-1}\right)$ & $86.6 \pm 3.8$ & $88.8 \pm 5.6$ & $8.0 \pm 2.9$ & $7.9 \pm 3.2$ & 0.442 & 0.724 \\
\hline RDW (\%) & $13.7 \pm 1.0$ & $13.7 \pm 1.1$ & $13.7 \pm 0.8$ & $14.7 \pm 1.5^{\mathrm{e}}$ & 5.225 & 0.002 \\
\hline Platelet $\left(\times\left. 10^{9}\right|^{-1}\right)$ & $277.5 \pm 75.2$ & $247.8 \pm 73.7$ & $276.6 \pm 51.6$ & $256.0 \pm 91.5$ & 1.118 & 0.345 \\
\hline MPV (fL) & $8.6 \pm 1.2$ & $8.6 \pm 1.1$ & $8.6 \pm 0.7$ & $8.6 \pm 0.9$ & 0.021 & 0.996 \\
\hline
\end{tabular}

Abbreviations: BUN, blood urea nitrogen; $\mathrm{CH}$, concentric hypertrophy; $\mathrm{CR}$, concentric remodeling; DBP, diastolic blood pressure; EH, eccentric hypertrophy; $\mathrm{f}$, $\mathrm{f}$ distribution; HBG, Hemoglobuline; HDL-C, high density lipoprotein cholesterol; HTC, Hemotocrite; LDL-C, low density lipoprotein cholesterol; MPV, mean platelet volume; NG, normal geometry; RDW, Red blood cell distribution width; SBP, systolic blood pressure; TChol, total cholesterol; TG, triglyceride; WBC, White blood cell.

a $P=0.002$ vs. $\mathrm{CH}$ group.

${ }^{\mathrm{b}} P=0.005$ vs. $\mathrm{CH}$ group. $P=0.01$ vs. $\mathrm{CR}$ group. $P=0.02$ vs. EH group.

${ }^{\mathrm{c}} P=0.018$ vs. $\mathrm{CH}$ group. $P=0.03$ vs. $\mathrm{CR}$ group.

$\mathrm{d} P=0.04$ vs. $\mathrm{CH}$ group.

${ }^{\mathrm{e}} P=0.004$ vs. EH group. $P=0.005$ vs. NG group. $P=0.007$ vs. CR group.

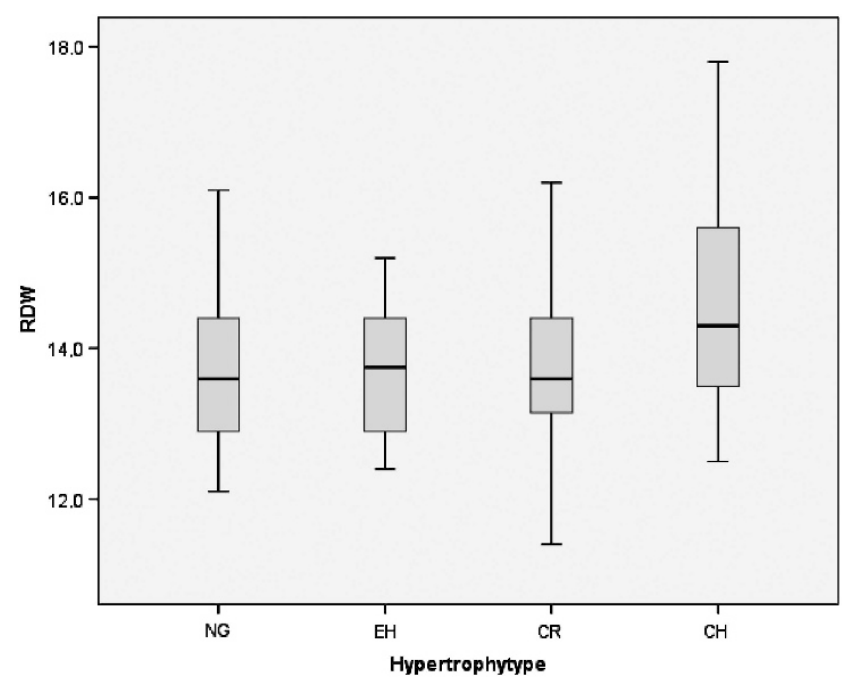

Figure 1 RDW levels along with left ventricle geometric patterns. A full color version of this figure is available at Hypertension Research online.

patients. Our Hospital Ethics Committee approved the study, and written informed consent for participation in the study was obtained from all of the participants. Patients with a history of chronic HT receiving appropriate antihypertensive medications, a history of secondary HT, pregnancy-induced HT and white coat HT, echocardiographic (left ventricle ejection fraction $<50 \%$ ) and clinical ( $\geqslant$ New York Health Association class II) evidence of heart failure, a history of acute coronary syndrome, ischemic ECG findings, significant coronary artery disease in coronary angiography ( $>50 \%$ luminal stenosis), organic valvular heart disease, chronic renal insufficiency (serum creatinine $>1.5 \mathrm{mg} \mathrm{dl}^{-1}$ in men, $>1.3 \mathrm{mg} \mathrm{dl}^{-1}$ in women) and a history of major noncardiovascular diseases such as autoimmune diseases, hematological diseases, cancer, thrombocytopenia and systemic inflammatory conditions were excluded from this study.

\section{Anthromorphometry, BP measurement}

After a 30-minute resting period, BP was measured twice in both arms while sitting using a mercury sphygmomanometer and $\sim$ sized cuffs. The average of the two highest BP measurements was used to calculate systolic and diastolic BP. Patients with a systolic BP $\geqslant 140 \mathrm{~mm} \mathrm{Hg}$ and/or a diastolic BP $\geqslant 90 \mathrm{~mm}$ $\mathrm{Hg}$ were considered to have HT.

Body mass index was computed as weight divided by height squared $\left(\mathrm{kg} \mathrm{m}^{-2}\right)$. The body surface area (BSA) was calculated using the Dubois formula of $\mathrm{BSA}=71.84 \mathrm{~W}^{.425} \mathrm{H}^{725}$ where $\mathrm{W}$ is weight in kilograms and $\mathrm{H}$ is height in centimeters. ${ }^{13}$ Waist circumference (in centimeters) was measured from the midpoint between the lowest rib and the iliac crest, while the subject was standing.

\section{Blood samples}

Blood samples were drawn in the morning after a 20-minute rest following a fasting period of $12 \mathrm{~h}$. Serum glucose, creatinine and lipid profiles were analyzed for each patient. RDW was measured from tripotassium ethylenediaminetetraacetic acid-based anticoagulated blood samples stored at $+4{ }^{\circ} \mathrm{C}$ and assessed by a Sysmex K-1000 autoanalyzer (Block Scientific, Bohemia, NY, USA) within $30 \mathrm{~min}$ of sampling.

\section{Echocardiography}

An echocardiographic examination was performed in all study subjects using a commercially available system (Vivid 7R GE Medical System, Horten, Norway) with a $2-3.5 \mathrm{MHz}$ transducer. M-mode echocardiographic measurements were obtained on the basis of the standards of the American Society of Echocardiography. ${ }^{14}$ Left atrial diameter, left ventricular diameter in end diastole and end systole (LVEDD, LVESD), interventricular septal thickness and posterior wall thickness (PWT) were measured. LV ejection fraction was determined by the biplane Simpson's method. ${ }^{15}$ LVM (g) was calculated using the Devereux formula: LVM $(\mathrm{g})=0.8 \times 1.04 \times$ $\left[(\mathrm{LviDD}+\mathrm{IVS}+\mathrm{PWT})^{3}-\mathrm{LviDD}^{3}\right]+0.6 .{ }^{16}$ Then, the LV mass index (LVMI, $\mathrm{g} \mathrm{m}^{-2}$ ) was obtained using the following formula: LVM/body surface area. LVH was defined according to more stringent criteria as LVMI values exceeded $125 \mathrm{~g} \mathrm{~m}^{-2}$ in men and $110 \mathrm{~g} \mathrm{~m}^{-2}$ in women. ${ }^{17}$ Relative wall thickness (RWT) was measured at end diastole as the ratio of $(2 \times \mathrm{PWT}) / \mathrm{LVEDD}$. Increased 
Table 2 Comparison of echocardiographic parameters

\begin{tabular}{|c|c|c|c|c|c|c|}
\hline Variables & $N G$ group $(\mathrm{n}=36)$ & $C R$ group $(\mathrm{n}=35)$ & EH group $(\mathrm{n}=30)$ & $\mathrm{CH}$ group $(\mathrm{n}=38)$ & $f$ & P-value \\
\hline LVSD (mm) & $26.1 \pm 4.6^{d}$ & $25.4 \pm 4.4^{e}$ & $30.4 \pm 2.8^{f}$ & $28.5 \pm 3.7$ & 9.05 & $<0.001$ \\
\hline PWT (mm) & $9.2 \pm 0.8^{i}$ & $10.7 \pm 1.1$ & $10.7 \pm 0.7$ & $12.2 \pm 1.2^{\mathrm{j}}$ & 51.95 & $<0.001$ \\
\hline $\mathrm{RVDD}(\mathrm{mm})$ & $24.5 \pm 4.1$ & $24.8 \pm 3.5$ & $27.2 \pm 3.9^{k}$ & $25.5 \pm 3.3$ & 2.53 & 0.06 \\
\hline LV MASS (g) & $139.6 \pm 29.1^{\prime}$ & $159.9 \pm 36.6^{m}$ & $206.4 \pm 29.1$ & $218.2 \pm 44.5$ & 36.61 & $<0.001$ \\
\hline $\mathrm{LAD}(\mathrm{mm})$ & $35.9 \pm 6.8$ & $35.1 \pm 6.2^{\mathrm{t}}$ & $38.2 \pm 3.9$ & $37.9 \pm 4.4$ & 2.39 & 0.07 \\
\hline LAVI $\left(\mathrm{ml} \mathrm{m}^{-2}\right)$ & $31.0 \pm 0.7$ & $28.1 \pm 0.4$ & $31.0 \pm 0.6$ & $30.1 \pm 0.6$ & 1.94 & 0.25 \\
\hline $\operatorname{LVEF}(\%)$ & $61.6 \pm 3.5$ & $60.8 \pm 2.7$ & $62.0 \pm 4.4$ & $60.5 \pm 6.7$ & 0.66 & 0.57 \\
\hline Assendan aorta $(\mathrm{mm})$ & $28.4 \pm 4.0^{\mathrm{u}}$ & $30.2 \pm 4.7$ & $30.2 \pm 4.3$ & $31.3 \pm 5.1$ & 2.57 & 0.05 \\
\hline $\mathrm{E} / \mathrm{A}$ & $0.98 \pm 0.1$ & $1 \pm 0.04$ & $1 \pm 0.08$ & $0.95 \pm .16$ & 1.03 & 0.38 \\
\hline $\operatorname{Dec} T(\mathrm{~ms})$ & $266.8 \pm 23.1$ & $261.5 \pm 20.3$ & $260.7 \pm 23.5$ & $265.6 \pm 35.1$ & 0.26 & 0.84 \\
\hline $\mathrm{e}^{\prime} / \mathrm{a}^{\prime}$ & $1 \pm 0.1$ & $0.99 \pm 0.1$ & $1.01 \pm 0.1$ & $0.96 \pm 0.1$ & 0.517 & 0.67 \\
\hline
\end{tabular}

Abbreviations: A, Mitral late diastolic velocity; $\mathrm{a}^{\prime}$, Mitral annular late diastolic velocity; $\mathrm{CH}$, concentric hypertrophy; $\mathrm{CR}$, concentric remodeling; Dec T, deceleration time; $\mathrm{E}$, Mitral early diastolic velocity; $e^{\prime}$. Mitral annular early diastolic velocity; EH, eccentric hypertrophy; $f$, $f$ distribution; IVST, interventricular septal thickness; LAD, Left atrial diameter; LAVI, Left atrial volume indices; LVDD, left ventricle diastolic diameter; LVEF, Left ventricle ejection fraction; LV MASS, Left ventricle mass; LVMI, left ventricular mass index; LVSD, Left ventricle systolic diameter; NG, normal geometry; PWT, posterior wall thickness; RVDD, Right ventricle diastolic diameter; RWT, relative wall thickness; Sm', Mitral annular systolic velocity.

${ }^{2} P<0.001$ vs. EH and CR groups. $P=0.03$ vs. $\mathrm{CH}$ group.

${ }^{\mathrm{b}} P<0.001$ vs. $\mathrm{CH}$ and $\mathrm{EH}$ groups.

c $P<0.001$ vs. $\mathrm{CH}$ group.

d $P<0.001$ vs. EH group. $P=0.02$ vs. $\mathrm{CH}$ group.

${ }^{\mathrm{e}} P<0.001$ vs. EH and $\mathrm{CR}$ groups.

${ }^{f} P<0.03$ vs. $\mathrm{CH}$ group.

$\mathrm{g} P<0.001$ vs. $\mathrm{EH}, \mathrm{CR}$ and $\mathrm{CH}$ groups.

$\mathrm{h} P<0.001$ vs. EH and CR groups.

i $P<0.001$ vs. $\mathrm{CH}, \mathrm{EH}$ and $\mathrm{CR}$ groups.

${ }_{\mathrm{j}} P<0.001$ vs. $\mathrm{EH}, \mathrm{CH}$ groups.

${ }^{\mathrm{k}} P=0.02$ vs. $\mathrm{EH} . P=0.03$ vs. $\mathrm{CR}$ group.

I $P<0.001$ vs. $\mathrm{EH}$ and $\mathrm{CH}$ groups. $P=0.01$ vs. CR group.

$\mathrm{m} P<0.001$ vs. EH and $\mathrm{CH}$ groups.

$\mathrm{n} P<0.001$ vs. $\mathrm{EH}$ and $\mathrm{CH}$ groups. $P=0.03$ vs. $\mathrm{CR}$ group

${ }^{\circ} P<0.001$ vs. $\mathrm{EH}$ and $\mathrm{CH}$ groups.

$\mathrm{P} P=0.008$ vs. $\mathrm{CH}$ group.

${ }^{\mathrm{q}} P<0.001$ vs. $\mathrm{CR}$ and $\mathrm{CH}$ groups. $P=0.04$ vs. EH group.

$r P<0.001$ vs. EH group. $P=0.04$ vs. $\mathrm{CH}$ group.

s $P<0.001$ vs. $\mathrm{CH}$ group.

${ }^{\mathrm{t}} P=0.03$ vs. NG group.

u $\mathrm{P}<0.08$ vs. $\mathrm{CH}$ group.

Table 3 Bivariate relationships of red-cell distribution width

\begin{tabular}{lcc}
\hline Variables & Pearson correlation coefficient & P-value \\
\hline AGE (year) & 0.293 & 0.001 \\
Systolic BP (mm Hg) & -0.01 & 0.911 \\
Diastolic BP (mm Hg) & -0.106 & 0.256 \\
IVST $(\mathrm{mm})$ & 0.199 & 0.036 \\
LVMI $\left(\mathrm{g} \mathrm{m}^{-2}\right)$ & 0.189 & 0.047 \\
RWT $(\mathrm{mm})$ & 0.06 & 0.532 \\
Hypertrophy type & 0.275 & 0.003 \\
Dec T (ms) & 0.133 & 0.257 \\
E/A & -0.177 & 0.131 \\
E/e' & 0.194 & 0.098 \\
$\mathrm{e}^{\prime} / \mathrm{a}^{\prime}$ & -0.193 & 0.1
\end{tabular}

Abbreviations: A, Mitral late diastolic velocity; $a^{\prime}$, Mitral annular late diastolic velocity; BP, Blood Pressure; Dec T, Deceleration time; E, Mitral early diastolic velocity; $\mathrm{e}^{\prime}$, Mitral BP, Blood Pressure; Dec T, Deceleration time; E, Mitral early diastolic velocity; e', Mitral
annular early diastolic velocity; HBG, Hemoglobuline; HTC, Hemotocrite; IVST, interventricula septal thickness; LVMI, left ventricular mass index; RWT, relative wall thickness.
RWT was defined as $>0.45 .{ }^{18}$ The left atrial volume was calculated using the area-length method. Using this method, the area of the left atrium was measured by planimetry of both apical views (A1 and A2). A linear dimension was measured from the center of the mitral annulus to the superior border of the chamber (litre). The left atrial volume was then calculated as $[(0.85 \times \mathrm{A} 1 \times \mathrm{A} 2) \div 1] .{ }^{19,28}$ The left atrial volume index was calculated by dividing the left atrial volume by the body surface area.

All of the echocardiography measurements were repeated in a second observer who was blinded to the values obtained from the first observer. Inter-observer variability was assessed by calculating the coefficient of variation. The coefficient of variation was $<8 \%$ for all measurements. Any discrepancy was resolved by consensus. All echocardiography measurements were repeated 1 week later in an observer blinded to the results of the previous measurements; intra-observer variability was $<5 \%$ for all measurements.

\section{Patterns of left ventricular geometry}

Geometric patterns were based on the upper normal limits for LVMI and RWT: (I) NG (normal LVMI and normal RWT); (II) CR (normal LVMI and 
increased RWT); (III) CH (increased LVMI and increased RWT) and (IV) EH (increased LVMI and normal RWT). ${ }^{18}$

\section{Statistical analysis}

Statistical analyses were performed using SPSS for Windows version 20.0 (SPSS, Chicago, IL, USA). The comparison of categorical variables between the groups was performed using the $\chi^{2}$-test. The Kolmogorov-Smirnov test was performed to evaluate the normality of distribution of all continuous variables. Analysis of variance was used in the analysis of continuous variables. Stratified post-hoc analyses of echocardiographic, clinical and laboratory variables were performed according to the LV geometric patterns. The correlations between RDW and laboratory, hemodynamic and echocardiographic parameters were assessed by the Pearson correlation test. To avoid over-fitting and collinearity in assessing the multivariate model, independent variables have been tested for inter-correlation. The cutoff value of the RDW for predicting the LV geometric pattern of $\mathrm{CH}$ with corresponding sensitivity and specificity was assessed using the receiver operating characteristic (ROC) curve analysis. The stepwise multiple linear regression analysis was performed to identify the independent associations of RDW. A two-tailed $P<0.05$ was considered to be statistically significant.

\section{RESULTS}

Four different geometric patterns were determined according to the LVMI and RWT; (1) 36 patients with NG, (2) 35 patients with CR, (3) 30 patients with EH and (4) 38 patients with $\mathrm{CH}$. Comparisons of baseline, clinical and laboratory characteristics are shown in Table 1. In comparison with the other groups, the highest RDW values were determined to be in the $\mathrm{CH}$ group $(P<0.01$, for all) (Figure 1$)$. The RDW values were similar among the NG, CR and EH groups. A comparison of the echocardiography parameters is illustrated in Table 2. LVMI and RWT values were highest in the $\mathrm{CH}$ group, followed by the $\mathrm{EH}, \mathrm{NG}$ and $\mathrm{CR}$ groups, respectively $(P<0.05$, for all). The prevalence of abnormal diastolic function showed nonsignificant stepwise increase in the $\mathrm{CH}$ group. We compared the

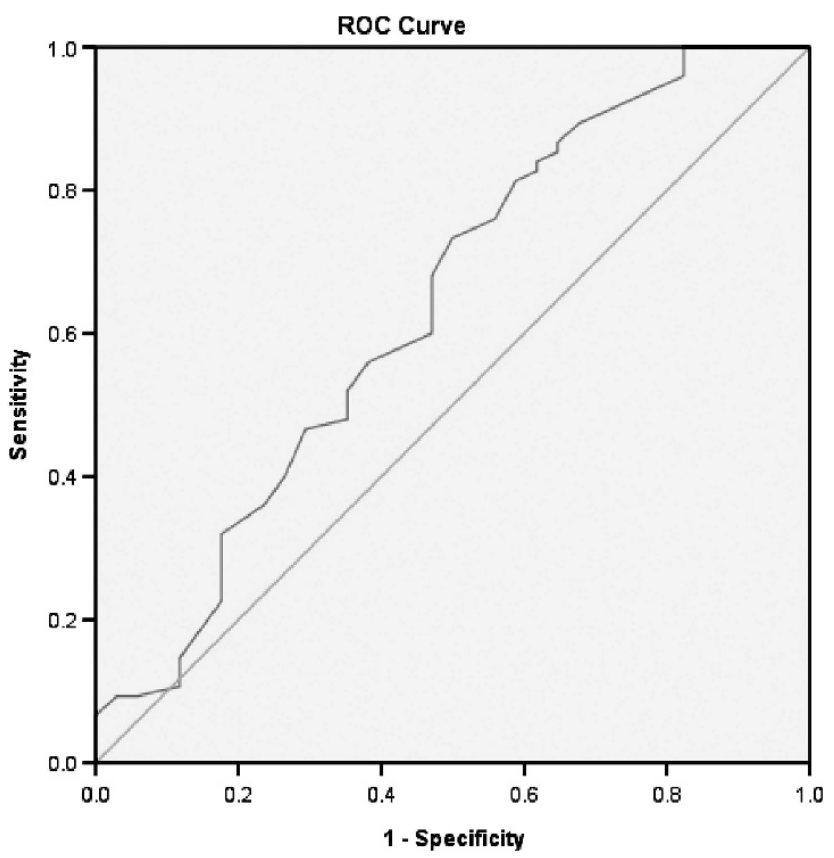

Figure 2 Receiver operating characteristic (ROC) curve analysis of the RDW predicting the concentric hypertrophy in patients with untreated essential hypertension. A full color version of this figure is available at Hypertension Research online. effects of dipping and nondipping patterns on RDW and no significant difference was detected $(13.9 \pm 1.1,14 \pm 1.3 ; P=0.45)$.

RDW was significantly correlated with age $(r=0.293, P<0.01)$, LVMI $(r=0.189, P=0.04)$ and interventricular septal thickness $(r=0.199, P=0.03)$ (Table 3$)$. It was observed that age $(\beta=0.309$, $P<0.001)$, RWT $(\beta=-0.278, P=0.02)$ and type of hypertrophy ( $\beta=0.408, P<0.001)$ were independent predictors of increased RDW value.

In receiver operating characteristic curve analysis, a level of RDW $>14.5$ predicted $\mathrm{CH}$ with $81 \%$ sensitivity and $59 \%$ specificity, and its area under curve: $0.636,95 \% \mathrm{CI}=0.518-0.755, P=0.02$ ) (Figure 2).

\section{DISCUSSION}

The present study provides the first data on the relationship between RDW and abnormal LV geometric patterns in patients with untreated essential HT independent of anemia. We demonstrated that RDW increased in the $\mathrm{CH}$ group but was similar in the NG, CR and $\mathrm{EH}$ groups. In addition, we demonstrated a significant stepwise increase in LVMI and RWT within the CH group.

Arterial HT is associated with a spectrum of cardiac geometric adaptations matched to systemic hemodynamic and ventricular load. ${ }^{20}$ LVH is an important example of end-organ damage in patients with $\mathrm{HT}^{3}$ Increased LVM predicts a greater risk of CV events, independent of other risk factors. ${ }^{15,21}$ The LV may adapt to HT by developing $\mathrm{CH}, \mathrm{EH}, \mathrm{CR}$ or by retaining NG. ${ }^{22}$ Each geometric pattern is associated with a distinct combination of pressure and volume stimuli, contractile efficiency (reduced in those with $\mathrm{CH}$ or $\mathrm{CR}$ ) and prognosis. $\mathrm{CR}$ and $\mathrm{EH}$ are more common than the typical pattern of $\mathrm{CH}$ in patients with untreated $\mathrm{HT}^{23}$ Our results were comparable with previous data. In our study, LVMI and RWT were increased in the $\mathrm{CH}$ group. According to the previous data, subjects with $\mathrm{CH}$ had the worst prognosis, followed by those with $\mathrm{EH}, \mathrm{CR}$ and NG in a population-based sample of subjects without CV disease. ${ }^{3,24}$

Increased RDW is also related to oxidative stress and the release of cytokines in response to inflammation. Oxidative stress directly damages erythrocytes and causes shortening of erythrocyte survival, thereby resulting in the elevation of RDW. ${ }^{7}$ It has been consistently shown that RDW is closely related to the prognosis and long-term adverse events of CV diseases and heart failure. ${ }^{8,25,26}$ It was also previously shown that an increased RDW value was related to HT. ${ }^{10,11}$ Tanindi et al. ${ }^{9}$ demonstrated that RDW was higher in patients with prehypertension and HT compared with healthy controls independent of age, inflammatory status and anemia. The relationship between RDW and LV geometric patterns has not been studied in patients with untreated essential HT before. In our study, we demonstrated that RDW was increased in the $\mathrm{CH}$ group but was similar in the NG, CR and EH groups. RDW was independently associated with types of LVH and RWT. Unlike other studies, we demonstrated that RWT was related to concentric hypertrophy regardless of the BP level. There may be several possible explanations for the relation between red blood cells and LVH in HT. One tentative explanation is that red-cell $\mathrm{Li}^{+} / \mathrm{Na}^{+}$exchange is increased in patients with essential HT. High $\mathrm{Li}^{+} / \mathrm{Na}^{+}$counter transport reflects the abnormal kinetic properties of red-cell membrane $\mathrm{Na} / \mathrm{H}$ exchange. A widespread abnormality of $\mathrm{Na} / \mathrm{H}$ exchange could has a major role in the pathogenesis of $\mathrm{CV}$ diseases. $\mathrm{Na} / \mathrm{H}$ exchange is involved in the regulation of cell $\mathrm{pH}$ and cell volume in the cellular responses to hormones, mitogens and growth factors and in the renal reabsorption of $\mathrm{Na}$ and bicarbonate. ${ }^{27}$ Increased $\mathrm{Li}^{+} / \mathrm{Na}^{+}$exchange has been found with cardiac hypertrophy in resistant $\mathrm{HT}^{28}$ 
Previously, it has been shown that increased RDW was related to echocardiographic parameters in patients with diastolic heart failure. $^{29}$ However, in our study abnormal diastolic functions showed a stepwise increase in the $\mathrm{CH}$ group but this change did not reach statistical significance; we also did not find any relationship between RDW and diastolic function. LV diastolic functions are known to be deteriorated in hypertensive patients whether their LV mass is increased or normal. ${ }^{30}$ Therefore, the reason for finding no significant differences between the groups may be owing to the deterioration of diastolic functions in all of the patients because every patient in our study group had untreated essential HT.

\section{Limitation}

The small number of participants and lack of a control group are the main limitations of this study. This is a cross-sectional study, meaning it is evident whether higher RDW levels in patients with $\mathrm{CH}$ is a cause or a result. Larger prospective trials should be performed to explore this issue. We already know that RDW has been shown to be an inflammatory marker that is closely related to the prognosis and longterm adverse events of CV diseases. ${ }^{6,7}$ However, the lack of assessment of inflammatory markers such as hs-CRP and their relation to RDW is another limitation of the current study. Finally, LV mass and ejection fraction were calculated based on M-mode measurements. It is possible that three-dimensional ultrasound recordings or myocardial MRIs may give more appropriate results.

In conclusion, in patients with untreated essential HT, the highest $\mathrm{RDW}$ values were observed in the $\mathrm{CH}$ group when compared with other geometric patterns independent of anemia. RDW could be a predictor of end-organ damage in these patients. Further prospective studies with larger sample sizes are needed to shed light on the mechanisms underlying this association.

\section{CONFLICT OF INTEREST}

The authors declare no conflict of interest.

1 Kearney PM, Whelton M, Reynolds K, Muntner P, Whelton PK, He J. Global burden of hypertension: analysis of worldwide data. Lancet 2005; 365: 217-223.

2 MacMahon S, Peto R, Cutler J, Collins R, Sorlie P, Neaton J, Abbott R, Godwin J, Dyer A, Stamler J. Blood pressure stroke coronary heart disease. Part 1 prolonged differences in blood pressure: prospective observational studies corrected for the regression dilution bias. Lancet 1990; 335: 765-774.

3 Devereux RB, De Simone G, Ganau A, Roman MJ. Left ventricular hypertrophy and geometric remodeling in hypertension: stimuli, functional consequences and prognostic implications. Journal of hypertension. J Hypertens Supp/ 1994; 12: 117-127.

4 Devereux RB, De Simone G, Ganau A, Koren MJ, Mensah GA, Roman MJ. Left ventricular hypertrophy and hypertension. Clin Exp Hypertens 1993; 15: 1025-1032.

5 Means Jr RT. Free and easy? red cell distribution width (RDW) and prognosis in cardiac disease. J Card Fail 2011; 17: 299-300.

6 Evans TC, Jehle D. The red blood cell distribution width. J Emerg Med 1991; 9 : 71-74.

7 Friedman JS, Lopez MF, Fleming MD, Rivera A, Martin FM, Welsh ML, Boyd A, Doctrow SR, Burakoff SJ. SOD2-deficiency anemia: protein oxidation and altered protein expression reveal targets of damage, stress response, and antioxidant responsiveness. Blood 2004; 104: 2565-2573.

8 Tonelli M, Sacks F, Arnold M, Moye L, Davis B, Pfeffer M. Relation between red blood cell distribution width and cardiovascular event rate in people with coronary disease. Circulation 2008; 117: 163-168.
9 Tanindi A, Topal FE, Topal F, Celik B. Red cell distribution width in patients with prehypertension and hypertension. Blood Press 2012; 21: 177-181.

10 Ozcan F, Turak O, Durak A, Işleyen A, Uçar F, Ginis Z, Uçar F, Başar FN, Aydoğdu S. Red cell distribution width and inflammation in patients with non-dipper hypertension. Blood Press 2013; 22: 80-85.

11 Perlstein TS, Weuve J, Pfeffer MA, Beckman JA. Red blood cell distribution width and mortality risk in a community based prospective cohort. Arch Int Med 2009; 169. 588-594.

12 Mancia G, Facchetti R, Bombelli M, Grassi G, Sega R. Long-term risk of mortality associated with selective and combined elevation in office, home, and ambulatory blood pressure. Hypertension 2006; 47: 846-853.

13 Du Bois D, Du Bois EF. A formula to estimate the approximate surface area if height and weight be known. 1916. Nutrition 1989; 5: 303-311.

14 Lang RM, Bierig M, Devereux RB, Flachskampf FA, Foster E, Pellikka PA, Picard MH Roman MJ, Seward J, Shanewise JS, Solomon SD, Spencer KT, Sutton MS, Stewart WJ, Chamber Quantification Writing Group; American Society of Echocardiography's Guidelines and Standards Committee; European Association of Echocardiography. Recommendations for chamber a quantification: a report from the American Society of Echocardiography's Guidelines and Standards Committee and the Chamber Quantification Writing Group, developed in conjunction with the European Association of Echocardiography, a branch of the European Society of Cardiology. J Am Soc Echocardiogr 2005; 18: 1440-1463.

15 Schiller NB, Shah PM, Crawford M, DeMaria A, Devereux R, bFeigenbaum H Gutgesell H, Reichek N, Sahn D, Schnittger I. Recommendations for quantitation of the left ventricle by two-dimensional echocardiography. American Society of Echocardiography Committee on Standards, Subcommittee on Quantitation of Two-Dimensional Echocardiograms. J Am Soc Echocardiogr 1989; 2: 358-367.

16 Devereux RB, Reichek N. Echocardiographic determination of left ventricular mass in man. Anatomic validation of the method. Circulation 1977; 55: 613-618.

17 European Society of Hypertension-European Society of Cardiology Guidelines Committee 2003 European Society of Hypertension-European Society of Cardiology guidelines for management of arterial hypertension. J Hypertens 2003; 21: 1011-1053.

18 Ganau A, Devereux RB, Roman MJ, de Simone G, Pickering TG, Saba PS, Vargiu P, Simongini I, Laragh JH. Patterns of left ventricular hypertrophy and geometric remodeling in essential hypertension. J Am Coll Cardiol 1992; 19: 1550-1558.

19 Pritchett AM, Jacobsen SJ, Mahoney DW, Rodeheffer RJ, Bailey KR, Redfield MM. Left atrial volume as an index of left atrial size: a population-based study. J Am Coll Cardiol 2003; 41: 1036-1043.

20 Bella JN, Wachtell K, Palmieri V, Liebson PR, Gerdts E, Ylitalo A, Koren MJ, Pedersen OL, Rokkedal J, Dahlöf B, Roman MJ, Devereux RB. Relation of left ventricular geometry and function to systemic hemodynamics in hypertension: The LIFE Study. J Hypertens 2001; 19: 127-134.

21 Koren MJ, Devereux RB, Casale PN, Savage DD, Laragh JH. Relation of left ventricular mass and geometry to morbidity and mortality in uncomplicated essential hypertension. Ann Intern Med 1991; 114: 345-352.

22 Silangei LK, Maro VP, Diefenthal H, Kapanda G, Dewhurst M, Mwandolela H, Hamel B. Assessment of left ventricular geometrical patterns and function among hypertensive patients at a tertiary hospital, Northern Tanzania. BMC Cardiovasc Disord 2012; 12 . 109

23 Ganau A, Devereux RB, Roman MJ, de Simone G, Pickering TG, Saba PS, Vargiu P, Simongini I, Laragh JH. Patterns of left ventricular hypertrophy and geometric remodeling in essential hypertension. J Am Coll Cardiol 1992; 19: 1550-1558.

24 Krumholz HM, Larson M, Levy D. Prognosis of left ventricular geometric patterns in the Framingham Heart Study. J Am Coll Cardiol 1995; 25: 879-884.

25 Yu SB, Cui HY, Qin M, Liu T, Kong B, Zhao QY, Huang H, Huang CX. Impact of red cell distribution width on outcome of 16681 patients with chronic systolic heart failure. Zhonghua xin xue guan bing za zhi 2012; 40: 237-242.

26 Cauthen CA, Tong W, Jain A, Tang WH. Progressive rise in red cell distribution width is associated with disease progression in ambulatory patients with chronic heart failure. J Card Fail 2012; 18: 146-152.

27 Semplicini A, Marzola M, Mozzato G. Ceolotto G, Pessina AC. Red blood cell $\mathrm{Li}+/ \mathrm{Na}+$ exchange in patients with diabetic nephropathy and essential hypertension: therapeutic implications. Renal failure 1993; 15: 331-338.

28 Semplicini A, Sartori M, Ceolotto G, Calò LA. The Li $+/ \mathrm{Na}+$ exchange in hypertension. Front Biosci 2003; 8: 912-929.

29 Celik A, Koc F, Kadi H, Ceyhan K, Erkorkmaz U, Burucu T, Karayakali M, Onalan O. Relationship between red cell distribution width and echocardiographic parameters in patients with diastolic heart failure. Kaohsiung J Med Sci 2012; 28: 165-172.

30 Altınmakas S, Yıldız S, Ogus T, Uyan C, Gunduz H, Keser N, Pektas O. Relationship between regional diastolic function and left ventricular mass in essential hypertension. Türk Kardiyol Dern Arș 2000; 28: 678-683. 